\title{
Experimental research on the process of cutting transport belts
}

\author{
Dominik Wilczyński ${ }^{1}{ }^{*}$, Ireneusz Malujda ${ }^{1}$, Jan Górecki ${ }^{1}$, Grzegorz Domek ${ }^{2}$ \\ ${ }^{1}$ Poznan University of Technology, Chair of Basics of Machine Design, Piotrowo Str. 3, Poland \\ ${ }^{2}$ Kazimierz Wielki University in Bydgoszcz
}

\begin{abstract}
The work presents the construction of a device designed to perform the cross-cutting process of conveyor belts. The device is equipped, among others, with a pneumatic drive in the form of a double acting piston rod. This actuator ensures reciprocating movement of the knife. The paper also presents the results of the pressure changes in the working chambers of the actuator as a function of displacement, recorded during the working movement of the knife which it performs during the cutting process. The tests were carried out in order to assess the level of pressures in the cylinder chambers during the cutting of belts of various constructions. These values were converted into cutting force values. It is important from the point of evaluation of changes in the value of cutting force of belts characterized by a different internal structure (composite belts made of different materials) and total thickness.
\end{abstract}

Keywords: cutting, transport belts, cutting force

\section{Introduction}

The belts which are a semi-finished product to make conveyor belts are subject to numerous processes during manufacturing. Generally speaking, one can identify three stages of production: cutting the belt to specific length and width, modification of the belt structure, e.g. through perforation $[1,2]$, milling, applying layers, etc. as well as connecting the band to form a continuous belt, mechanically or through welding [3]. Due to the constant improvement of the mechanical properties of composite polymer belts and a variety of used materials and structures, the above mentioned processes, including cutting, are a source of numerous problems for the global belt manufacturers [1,2]. For this reason, it is necessary to examine the influence of the used tools and equipment as well as the technological parameters on the course of the process in order to improve it.

Polymer conveyor belts can be divided into three basic groups (Fig. 1): flexible belts with low strength (Fig. 1a), which are made of layers of polyurethane or PVC as well as fabric, e.g. polyester, as well as strong and rigid belts in which the base layer is the polyamide foil reinforced with polyamide fabric (Fig. 1b) as well as flexible belts with improved resistance,

\footnotetext{
* Corresponding author: dominik.wilczynski@put.poznan.p1

Reviewers: Marian Dudziak, Milan Vaško
} 
reinforced with aramid, carbon or steel fiber cord (Fig. 1c). The third group is mostly utilized as toothed belts. Regardless of the group, belt coating is made with materials enabling sufficient friction coefficient - mostly NBR rubber, fabric, PVC or polyurethane [2, 4-6].
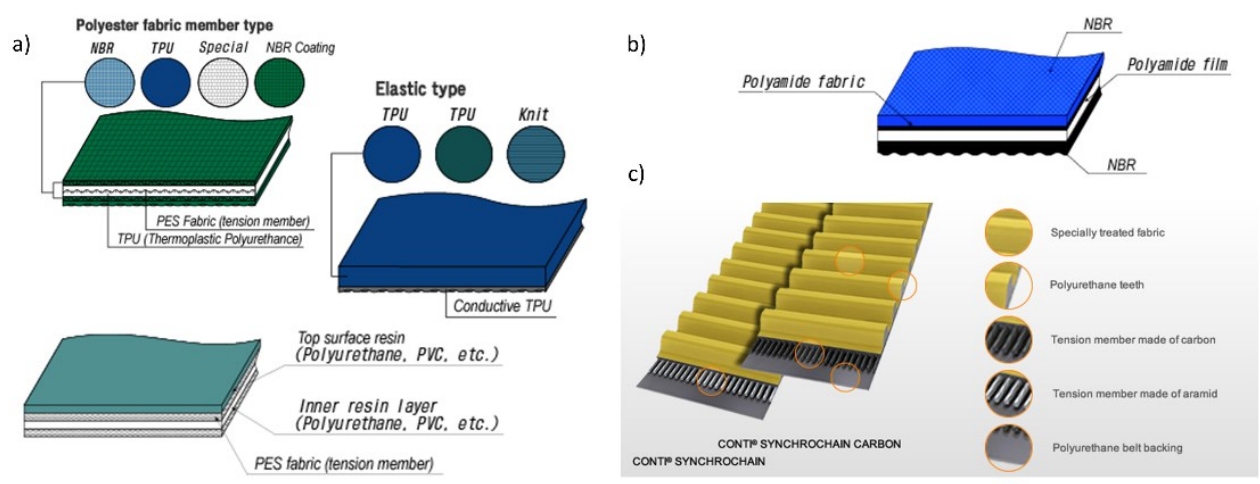

Fig. 1. The composition of polymer and composite conveyor belts based on the following examples: Nitta Polysprint ${ }^{\circledR}$ and New Light Grip ${ }^{\circledR}$ (a), Nitta Polybelt ${ }^{\circledR}$ (b) as well as Conti Synchrochain ${ }^{\circledR}$ (c) $[7,8]$

If an automated solution is used to perforate the belt, proper execution of the cutting process can significantly affect its course, as edges created at this point are used as the basis for calculating the coordinates for the openings and ensure that the belt is correctly driven through the machine. Two cutting methods can be used for the belts: slitting and guillotining $[9,10]$. Due to the high degree of width variance as well as significant belt flexibility and simple kinematics, fixed or rotating circular knives are most often used. The process cutting force is primarily affected by blade geometry, but also the properties of cut materials [11].

The main objective of this article is to present the effect of the belt type on the cutting force value as well as testing the prototype of the designed machine in order to adapt it to different types of belts. Section 2 describes the construction of the prototype together with the testing methodology used when performing measurements. The examination results together with a complete analysis are presented in chapter 3 , the most important conclusions were presented in section 4 (Conclusions).

\section{Testing station and study methodology}

The station to perform the tests was one of the modules of an industrial grade machines used for perforating conveyor belts (Fig. 2). 


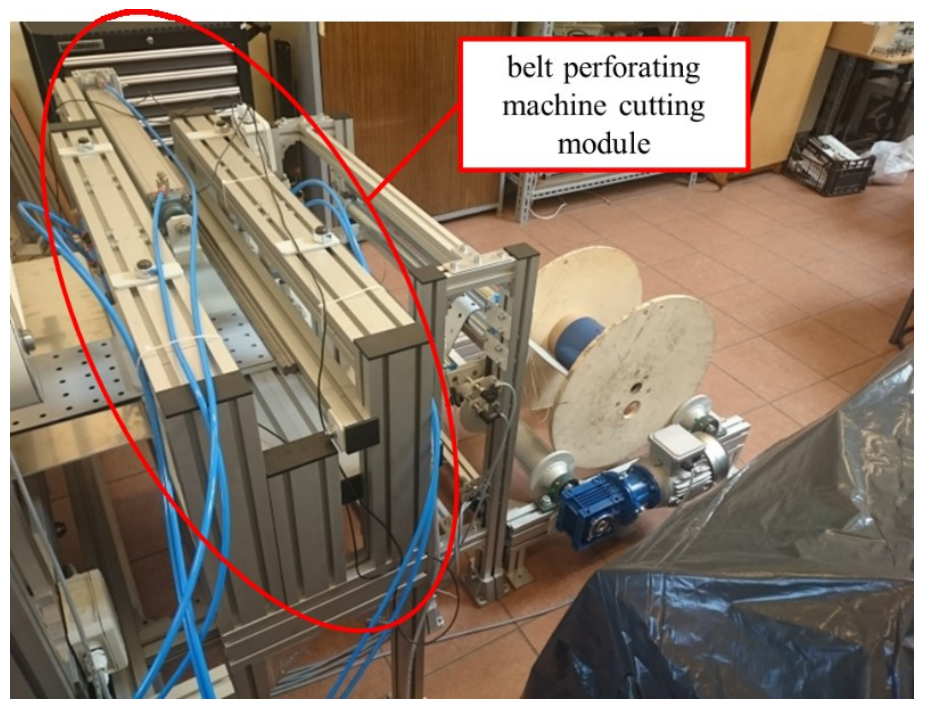

Fig. 2. General view of the conveyor belt perforation machine with indicated cutting module which was used in experimental testing

The pneumatic cylinder enabling the reciprocating motion of the knife with diameter $\varnothing 100 \mathrm{~mm}$ (Fig. 2). The blade penetrates approx. $3 \mathrm{~mm}$ into the polyamide plate on which the belt is placed. Before starting the cutting process, the belt is simultaneously pressed.

Piezoresistive pressure sensors by Keller were installed on the connecting piece to the working chamber of the pneumatic cylinder actuating the reciprocating motion of the knife with outgoing voltage signal connected directly to the data acquisition card. This allowed to record the data and further process it. Knife displacement was registered via string potentiometer (encoder) attached to the piston rod of pneumatic cylinder actuating the knife. This sensor also sends outgoing signal to the data acquisition card. Simultaneous acquisition of signal from the potentiometer and pressure sensors allowed to obtain the forcedisplacement characteristics which were presented at the subsequent figure.

The study results were used to calculate the force required to cut the conveyor belts with different construction (different materials and internal structure) and thickness. The studied belts are divided into three groups: strong flexible belts with polyurethane core reinforced with aramid fibers (cord), rigid, strong belts with polyamide core and flexible light belt with polyurethane core reinforced with polyester fabric. The cutting test for each belt acting as a representative sample for every group was repeated three times. The force was calculated indirectly based on the acquired pressure change graph in pneumatic cylinder working chambers. The analysis took into account the motion resistance force of the knife blade, which is partially sunken into the polyamide plate. To this end, three measurements were taken for the change in pressure value in the working chamber as the knife penetrated the plate with no belt present. The registered knife motion resistance force consists of frictional force of the knife blade on the polyamide plate, frictional force at the piston seal and piston rod seal of the pneumatic cylinder.

The blade penetrating into the plate is intended as it is acting as a guide and improves the quality of the cut belt edge (straight edge line).

The further part of this study presents and discusses the results of the examination. 


\section{Examination results and analysis}

The figures below show the characteristics of the change in the force value depending on the displacement of the pneumatic cylinder actuating the knife, which is equal to the displacement of the knife itself. All the presented characteristics are average values achieved by performing three test cuts for every belt.

Figure 3 shows the characteristics of the average force value change as a function of the displacement for the knife penetrating the polyamide plate with no belt present.

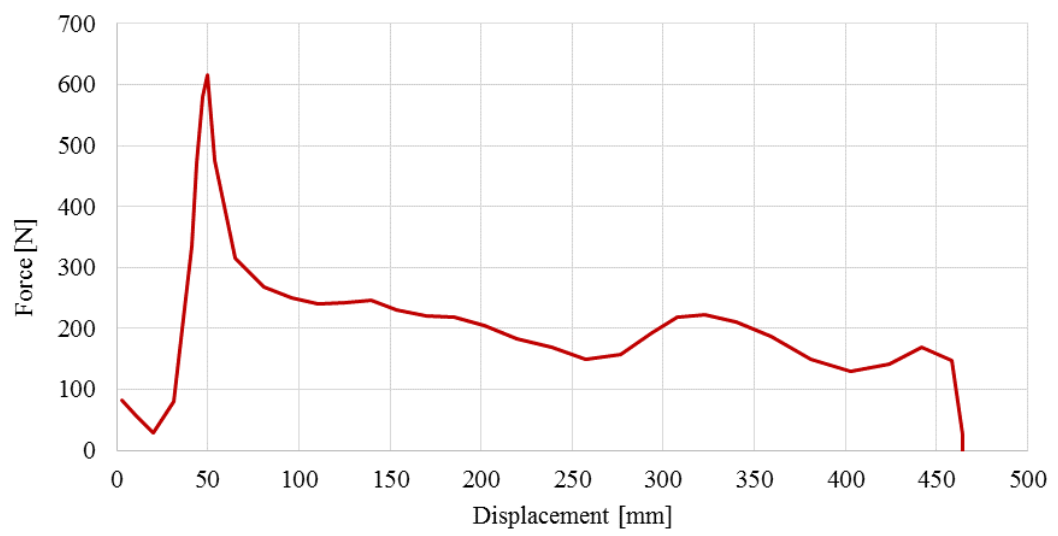

Fig. 3. Characteristic of the change of force value as a function of displacement of the knife for its penetration of the polyamide plate with no belt present

The maximum value at the above figure exceeding $600 \mathrm{~N}$ stands for the beginning of the knife blade penetrating the polyamide plate. This is caused by the fact that the knife is outside the plate outline (Fig. 2). At the moment when the knife motion begins, the blade traverses several dozen millimeters (Fig. 3) without coming into contact with another component. The registered force value of under $100 \mathrm{~N}$ is the force necessary to overcome the internal resistance of the pneumatic cylinder (Fig. 2). Only after traversing approx. $50 \mathrm{~mm}$, the knife blade begins to penetrate the plate material. The initial moment of the blade penetrating the polyamide plate makes for resistance equal to the force of approx. $616 \mathrm{~N}$. Afterwards, the force value decreases and its value stabilizes.

During examination of the force strength required to cut the belts, the belt was placed on the polyamide plate so that its edge is moved $10 \mathrm{~mm}$ away from the edge of the plate. This was necessary for the characteristics to differentiate between the point of penetrating the plate from the point of the blade already sunken in the plate penetrating the belt material.

The above is reflected at two points of the above graphs in which the force achieves the maximum value for the specific displacement. The first maximum value is the moment in which the blade penetrates the material of the polyamide plate, the second maximum is the beginning of penetration of the belt material.

Figure 4 presents the breakdown of the characteristics of the cutting force for light flexible belts. Five different belts were examined within this group. 


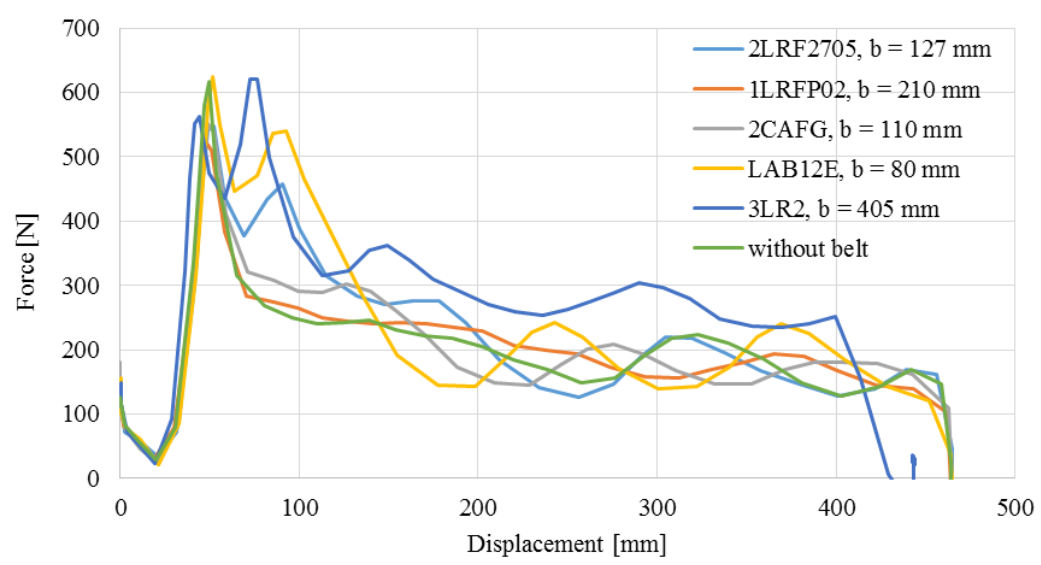

Fig. 4. Characteristics of the change of the cutting force for the group of light flexible belts

Figure 4 presents the change of force value as a function of the displacement for the five specimen of the light flexible belts group. The force required for cutting each belt is the difference between the maximum force value for that belt and the force determined by the resistance in knife motion in the polyamide plate without the belt. Therefore, the characteristics of force value change was compared to the resistance force of the knife motion. At the end of this chapter, the actual force values required to cut each of the belts will be presented. Based on the figure above, one needs to observe that the resistance force value of the knife in the polyamide plate exceeds the force value necessary to cut some of the belts, e.g. the belts 2 CAFG or 1LRFP02.

Figure 5 presents the breakdown of characteristics of the change of the cutting force for the strong rigid belts.

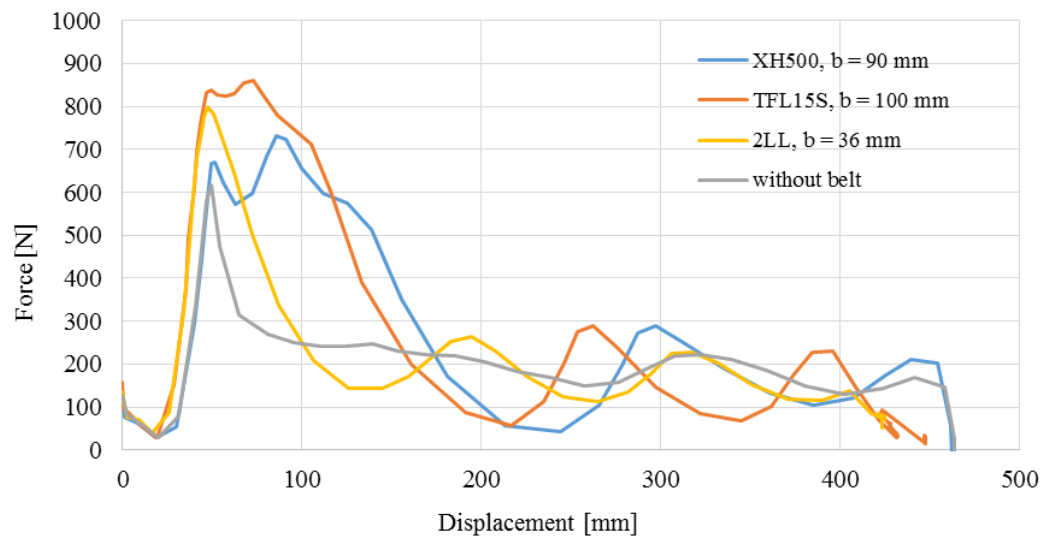

Fig. 5. Characteristics of change of the cutting force for strong rigid belts

The force required to cut the belts XH500, TFL15S and 2LL is greater than the knife motion resistance force. For the segment in which the knife has penetrated the belt, the cutting force decreases and stabilizes, momentarily as a result of the change in the value of knife and pneumatic cylinder motion resistance value, they exceed the value of the cutting force. 
During the next stage of the examination, the cutting force value required to cut the toothed belt from the strong flexible belts group reinforced with aramid fiber. The results of the examination are shown at Figure 6.

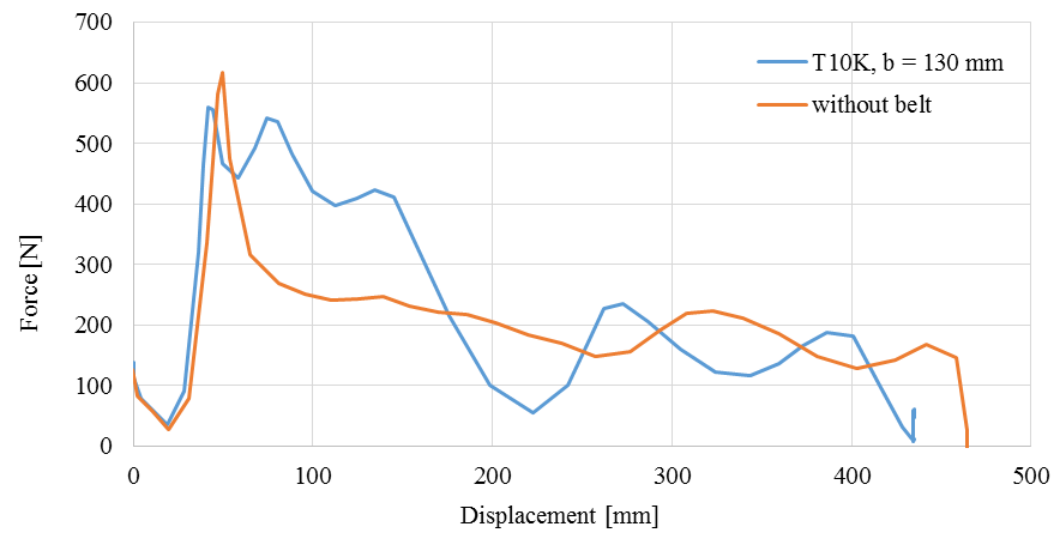

Fig. 6. Characteristics of the change in cutting force of the strong flexible belts

In the case of the $\mathrm{T} 10 \mathrm{~K}$ toothed belt, it is evident that the knife motion resistance forces exceed the force value required to cut it. As the knife displacement progresses, the resistance forces exceed or are momentarily lower than the value of the cutting force. This is caused by the system characteristics in which the resistance force components are the frictional force of the knife blade in the polyamide plate as well as the resistance due to friction on the piston seals and piston rod of the pneumatic cylinder.

Due to the fact that the cut belts have different width, it is necessary to determine the influence of the variable belt width on the cutting force value. The examination was carried out for the belt M350 as a specimen of the strong rigid belts. Figure 7 demonstrates the average values obtained from three tests for the cutting force measured for the belt M350 with width $53 \mathrm{~mm}, 142 \mathrm{~mm}$ and $320 \mathrm{~mm}$.

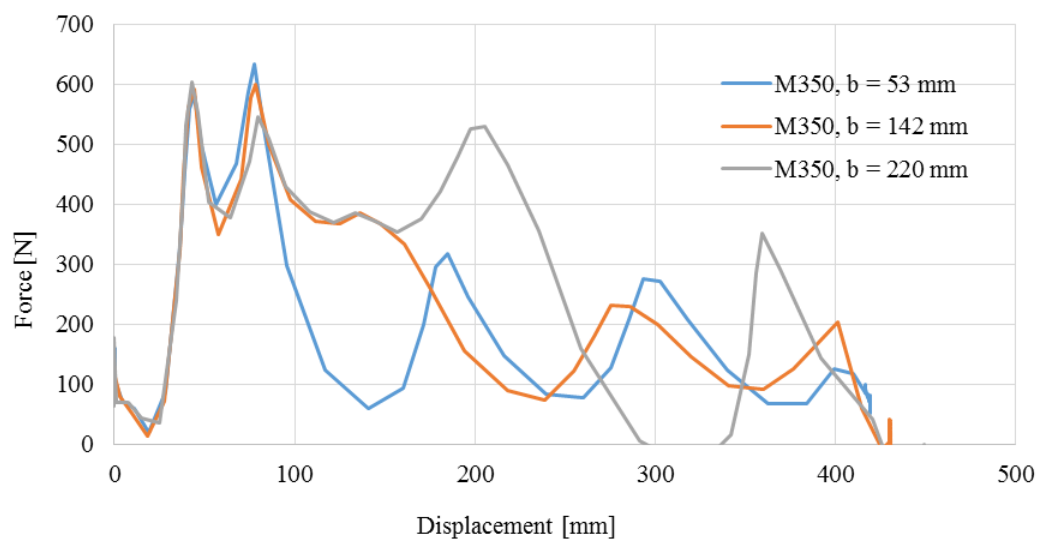

Fig. 7. The characteristics of change of the cutting force of the belt M350 from the group of strong rigid belts depending on its width

The cutting force value does not depend on belt width but on the strength of the materials used in its composite structure. This is clearly demonstrated on the figure above. 
Table 1 shows actual cutting force values required for cutting belts from each group.

Table 1. Breakdown of actual cutting force values for specific types of belts

\begin{tabular}{|c|c|c|c|}
\hline Type of belt & Name of belt & $\begin{array}{l}\text { Thickness of belt } \\
\text { [mm] }\end{array}$ & $\begin{array}{c}\text { Max. cutting } \\
\text { force value }[\mathbf{N}]\end{array}$ \\
\hline \multirow{5}{*}{$\begin{array}{c}\text { Light } \\
\text { flexible belt }\end{array}$} & 1LRFP02 & 0.9 & 30 \\
\hline & 2LRF2705 & 2 & 200 \\
\hline & 2CAFG & 2.1 & 60 \\
\hline & LAB12E & 2 & 280 \\
\hline & 3LR2 & 3 & 370 \\
\hline \multirow{4}{*}{$\begin{array}{l}\text { Strong rigid } \\
\text { belts }\end{array}$} & XH500 - 3 & $3(0.5)$ & 450 \\
\hline & TFL15S & $3.1(1.5)$ & 600 \\
\hline & $2 \mathrm{LL}$ & $5(1)$ & 520 \\
\hline & M350 & $2.35(0.35)$ & 330 \\
\hline $\begin{array}{l}\text { Aramid fibre } \\
\text { reinforced } \\
\text { polyurethane } \\
\text { belt }\end{array}$ & $\mathrm{T} 10 \mathrm{~K}$ & 4.5 & 300 \\
\hline
\end{tabular}

\section{Conclusions}

Based on the obtained research results, the following conclusions can be reached: - the value of knife movement resistance is about $50 \%$ of the cutting force of most belts, therefore it is necessary to investigate the effect of the penetration depth of the knife blade in the polyamide plate,

- the main impact on the value of the cutting force is the strength of the belt support layer (for all types), and in the case of belts with polyamide core, a linear relationship between the core thickness and the maximum cutting force value can be observed (Table 1), - the maximum cutting force occurs at the beginning of penetration of materials by the blade, which means that the width of the belt does not affect its value.

\section{References}

1. D. Wojtkowiak, K. Talaśka, I. Malujda, G. Domek, Analysis of the influence of the cutting edge geometry on parameters of the perforation process for conveyor and transmission belts. MATEC Web of Conferences 157, 01022 (2018)

2. D. Wojtkowiak, K. Talaśka, I. Malujda, G. Domek, Estimation of the perforation force for polymer composite conveyor belts taking into consideration the shape of the piercing 
punch. The International Journal of Advanced Manufacturing Technology 98, 9-12, 2539-2561 (2018) https://doi.org/10.1007/s00170-018-2381-3

3. K. Wałęsa, I. Malujda, K. Talaśka, Butt welding of round drive belts. Acta Mechanica et Automatica 12 (2), 115-126 (2018)

4. K. Talaśka, D. Wojtkowiak, Modelling a mechanical properties of the multilayer composite materials with the polyamide core. MATEC Web of Conferences 157, 02052 (2018)

5. M. Hardygóra, Taśmy przenośnikowe. Wydawnictwo Naukowo-Techniczne, Chapter 1 and 2, Warszawa (1999)

6. L. Gładyszewicz, Przenośniki Taśmowe - teoria i obliczenia. Wydawnictwo Politechniki Wrocławskiej (2003)

7. Wilhelm Herm. Müller, Nitta Industries - polish catalog, In: www.whm.pl (Access date: 06.08.2018)

8. https://www.contitech.de (Access date: 06.08.2018)

9. Tidland, A Guide to Slitting In: http://www.maxcessintl.com (Access date: 06.08.2018)

10. H. Wisselink, Analysis of Guillotining and Slitting Finite Element Simulations dissertation. University of Twente, The Netherlands (2000)

11. D. Wilczyński, K. Talaśka, I. Malujda, P. Jankowiak, Experimental research on biomass cutting process. MATEC Web of Conferences 157, 07016 (2018) 